\title{
Australian state influenza notifications and school closures in
}

\section{9 [version 1; peer review: 2 approved with reservations]}

\author{
Anna Mae Scott (D1), Mina Bakhit (D1, Justin Clark(D1, Melanie Vermeulen1, \\ Mark Jones ${ }^{1}$, David Looke2,3, Chris Del Mar', Paul Glasziou (iD)1 \\ ${ }^{1}$ Institute for Evidence-Based Healthcare, Bond University, Robina, Queensland, 4226, Australia \\ ${ }^{2}$ Department of Medicine, University of Queensland, St Lucia, Queensland, 4072, Australia \\ ${ }^{3}$ Infectious Disease and Clinical Microbiology, Princess Alexandra Hospital, Brisbane, Queensland, Australia
}

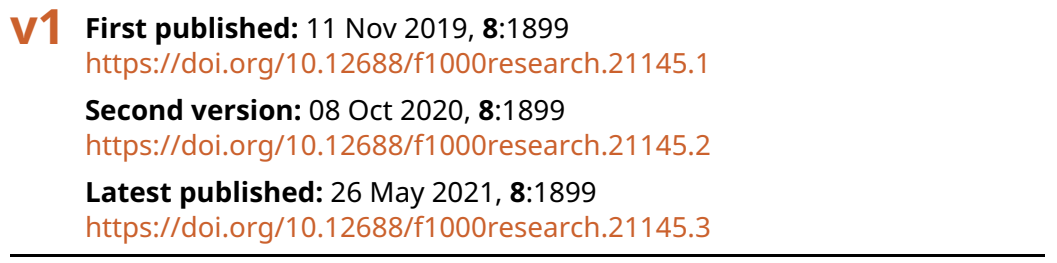

\section{Abstract}

Background: The impact of school holidays on influenza rates has been sparsely documented in Australia. In 2019, the early winter influenza season coincided with mid-year school breaks, enabling us the unusual opportunity to examine how influenza incidence changed during school closure dates.

Methods: The weekly influenza data from five Australian state and one territory health departments for the period of week 19 (mid-May) to week 35 (early September) 2019 were compared to each state's public school closure dates. We used segmented regression to model the weekly counts and a negative binomial distribution to account for overdispersion due to autocorrelation. The models' goodness-of-fit was assessed by plots of observed versus expected counts, plots of residuals versus predicted values, and Pearson's Chi-square test. The main exposure was the July two-week school vacation period, using a lag of one week. The effect is estimated as a percent change in incidence level, and in slope. We also dichotomized the change in weekly counts into decreases versus increases (or no change). The proportion of decreases were then compared for each of three periods (pre-vacation, vacation, post-vacation) using Fishers exact test. Results: School holidays were associated with significant declines in influenza incidence. The models showed acceptable goodness-of-fit. The numbers and percentages of decreases in weekly influenza counts from the previous week for all states combined were: $19(33 \%)$ pre-vacation; 11 (92\%) decreases during the vacation; and 19 (59\%) decreases post-vacation ( $P=0.0002)$. The first decline during school holidays is seen in the school aged (5-19 years) population, with the declines in the adult and infant populations being smaller and following a week later.

Conclusions: Given the significant and rapid reductions in incidence,

\section{Open Peer Review}

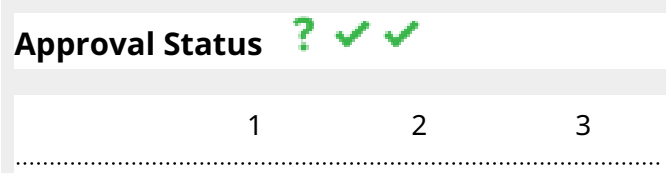

version 3

(revision)

26 May 2021

version 2

(revision)

08 Oct 2020

version 1

11 Nov 2019

1. Casey Zipfel ID, Georgetown University,

Washington, USA

Shweta Bansal ID, Georgetown University,

Washington, USA

2. Núria Torner iD, University of Barcelona,

Barcelona, Spain

3. August Wrotek ID, Centre of Postgraduate

Medical Education, Warsaw, Poland

Any reports and responses or comments on the article can be found at the end of the article. 
these results have important public health implications. Closure or extension of holiday periods could be an emergency option for state governments.

\section{Keywords}

Influenza, influenza epidemic, child, adolescent, school closure, school

holidays, absenteeism

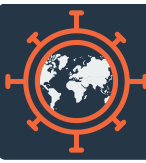

This article is included in the Emerging Diseases

and Outbreaks gateway.

\section{Corresponding author: Anna Mae Scott (ascott@bond.edu.au)}

Author roles: Scott AM: Data Curation, Investigation, Project Administration, Supervision, Writing - Original Draft Preparation, Writing Review \& Editing; Bakhit M: Data Curation, Investigation, Writing - Review \& Editing; Clark J: Data Curation, Investigation, Writing Review \& Editing; Vermeulen M: Data Curation, Investigation, Visualization, Writing - Review \& Editing; Jones M: Formal Analysis, Methodology, Visualization, Writing - Original Draft Preparation, Writing - Review \& Editing; Looke D: Conceptualization, Methodology, Writing - Original Draft Preparation, Writing - Review \& Editing; Del Mar C: Conceptualization, Methodology, Writing - Original Draft Preparation, Writing - Review \& Editing; Glasziou P: Conceptualization, Formal Analysis, Supervision, Writing - Original Draft Preparation, Writing - Review \& Editing

Competing interests: No competing interests were disclosed.

Grant information: The author(s) declared that no grants were involved in supporting this work.

Copyright: (c) 2019 Scott AM et al. This is an open access article distributed under the terms of the Creative Commons Attribution License , which permits unrestricted use, distribution, and reproduction in any medium, provided the original work is properly cited.

How to cite this article: Scott AM, Bakhit M, Clark J et al. Australian state influenza notifications and school closures in 2019 [version 1; peer review: 2 approved with reservations] F1000Research 2019, 8:1899 https://doi.org/10.12688/f1000research.21145.1

First published: 11 Nov 2019, 8:1899 https://doi.org/10.12688/f1000research.21145.1 


\section{Introduction}

In 2009, the United Kingdom experienced a summer influenza pandemic, with the National Health Service resorting to pharmacy dispensed oseltamivir to slow the growth. However, when schools closed in August for the six-week summer break, the epidemic dropped to almost zero within a few weeks ${ }^{1}$. This was an extreme example of an association that has been documented in other countries, though generally for shorter closures ${ }^{2-4}$. A 2013 review of both deliberate and non-deliberate school closures concluded that even without co-interventions, closure of schools could reduce flu transmission during an outbreak ${ }^{3,5}$.

The association of school closure and influenza rates has been only sparsely documented in Australia, partly because school holidays generally fall outside the peak influenza period. However, 2019 saw an early epidemic of influenza in Australia with rates around five times normal for the May-July period, with consequent hospitalisation and deaths also increased. Because of the early high rates, winter influenza in 2019 also coincided with the mid-year school breaks, which appeared to be associated with a dip in influenza incidence.

To explore any relationship between the holiday school closure and influenza cases, we examined the relationship between changes in influenza incidence with the school closure dates in 2019 using the different holiday dates that apply in the Australian states and territories.

\section{Methods}

\section{Setting}

Influenza is a notifiable disease in all Australian states and territories $^{6}$. We collected influenza data notified weekly to state and territory health departments, for the period of week 19 (mid-May) to week 35 (early September) 2019, which corresponds to the flu season in Australia.

We included data from five states (New South Wales, Queensland, Victoria, South Australia, Western Australia) and one territory (Australian Capital Territory); we excluded data from one state (Tasmania) and one territory (Northern Territory) due to paucity of available data and small population sizes.

\section{Data sources and extraction}

States and territories differ in how they collect and report data on flu cases. New South Wales ${ }^{7}$ and Queensland ${ }^{8}$ report the number of samples that test positive for Influenza $\mathrm{A}$ and B (lab-confirmed); Australian Capital Territory ${ }^{9}$ reports the number of influenza (lab) notifications to the state; and Western Australia $^{10}$, Victoria ${ }^{11}$ and South Australia ${ }^{12}$ report the number of lab-confirmed influenza cases (strains unspecified).

We collected flu data as it was reported by each jurisdiction. We collected data on public school closures between week 19 and week 35 from each state or territory's education department website.

Weekly, numerical flu data were available from reports produced by the Health Departments in New South Wales,
Queensland, Western Australia, Victoria, and Australian Capital Territory. For South Australia, the number of lab-confirmed influenza cases for weeks 19-24 were extracted from a figure (using webplotdigitiser ${ }^{13}$ ) since weekly numerical data were available only for weeks 25-35. Data on school holidays were extracted from each state or territory's website. Raw data are provided (see Data availability section) ${ }^{14}$.

\section{Statistical methods}

Due to differences in the population numbers of each state and territory, differences in the methods of data collection, and insufficient number of states to reliably fit a random effects model, analysis was conducted separately by state.

We used segmented regression ${ }^{15}$ to model the weekly counts and specified a negative binomial distribution to account for overdispersion due to autocorrelation. Explanatory factors included the linear effect of week (slope), initial effect of vacation (change in level), change in linear effect of week after start of vacation (change in slope), initial effect of returning to school, and change in linear effect of week after school return (Appendix 2, Extended data $)^{16}$. Goodness-of-fit of the models was assessed by plots of observed versus expected counts, plots of residuals versus predicted values, and Pearson's Chi-square test. The main exposure for our analysis was the July school vacation period of two weeks. Due to the delay from exposure to the virus to confirmation of infection status, we included a lag of one week ${ }^{17}$. The effect of school vacation is reported as a percentage change in level (with 95\% confidence interval) as well as a percentage change in slope (with 95\% confidence interval). We hypothesized that the vacation period (lagged by one week) would lead to reductions in weekly counts of influenza cases.

In a separate analysis, for each state, we calculated the change in weekly counts from the previous week and dichotomized into decreases versus increases (or no change). For example, a change from 100 influenza cases in the previous week to 50 influenza cases in the current week would be classified as a decrease. The proportion of decreases were then compared for each of three periods (pre-vacation, vacation, postvacation) using Fishers exact test.

Statistical analysis was conducted using SAS University Edition 9.4 for Windows.

\section{Results}

Figure 1 shows the rates of influenza for the included states and territory. Figures for each individual state or territory are provided in Appendix 3, Extended data ${ }^{16}$.

The estimates for the initial effect and the subsequent slopes (Table 1) show significant declines for all states except South Australia, which had already passed its peak by the time of the school holidays (Appendix 3, Extended data) ${ }^{16}$. The models showed acceptable goodness-of-fit (Appendix 4, Extended data $)^{16}$ with Pearson's Chi-square tests all indicating insufficient evidence of lack of fit $(\mathrm{P}>0.05)$. 


\section{Influenza reports by State}

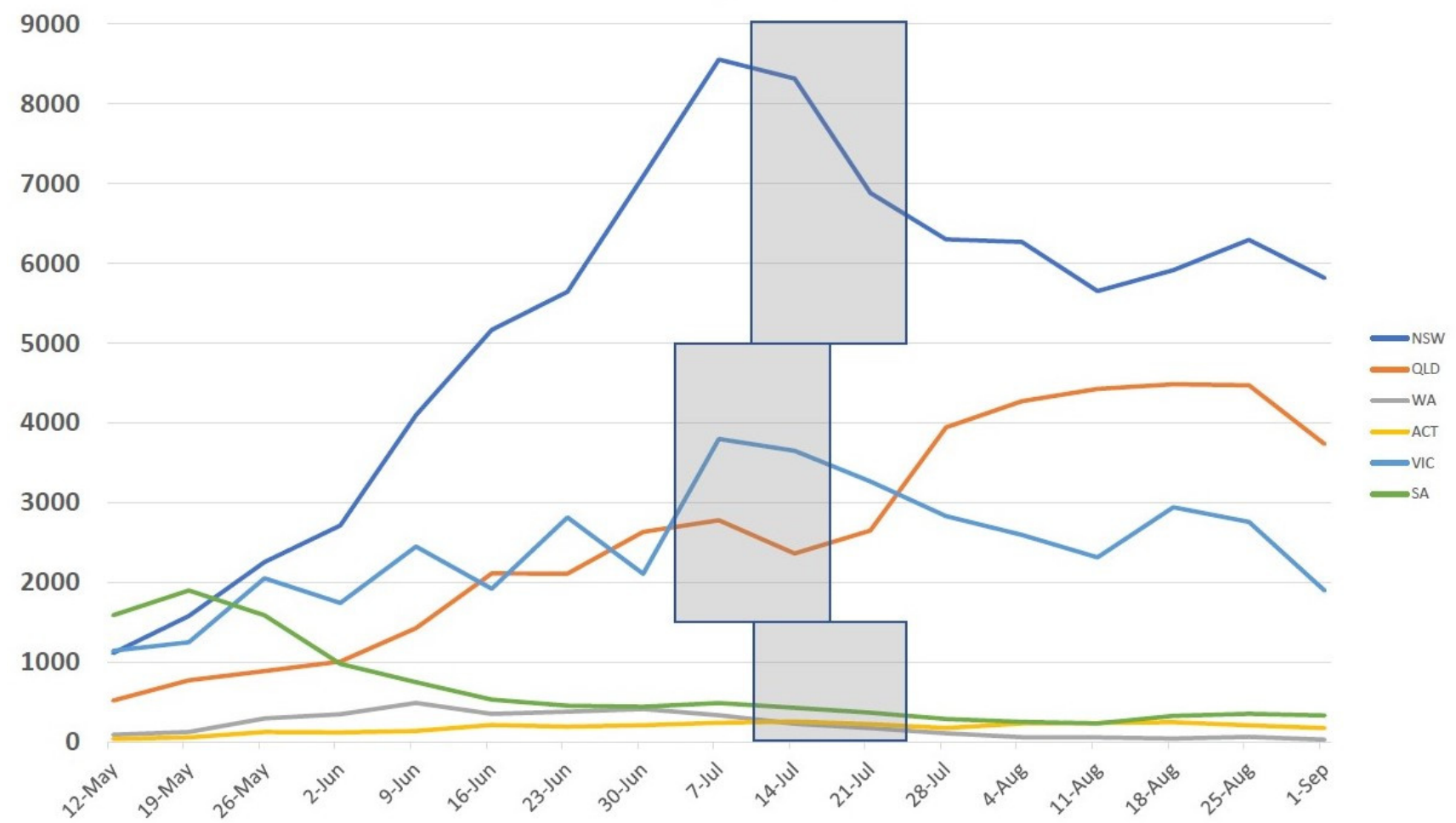

Figure 1. Rates of influenza for the included Australian states and territory (boxes show school holidays periods). NSW, New South Wales; QLD, Queensland; WA, Western Australia; ACT, Australian Capital Territory; VIC, Victoria; SA, Southern Australia.

Table 1. Estimates and 95\% confidence intervals from segmented
regression models of weekly influenza counts.
\begin{tabular}{|l|l|l|}
\hline State & $\begin{array}{l}\text { Change in level due to school } \\
\text { vacation* }\end{array}$ & $\begin{array}{l}\text { Change in slope due to } \\
\text { vacation* }\end{array}$ \\
\hline NSW & $-50 \%(-35 \%,-61 \%) ; P<0.0001$ & $-27 \%(-2 \%,-46 \%) ; P=0.037$ \\
\hline QLD & $-41 \%(-27 \%,-52 \%) ; P<0.0001$ & $-9 \%(15 \%,-29 \%) ; P=0.41$ \\
\hline VIC & $-2 \%(41 \%,-32 \%) ; P=0.91$ & $-21 \%(20 \%,-48 \%) ; P=0.27$ \\
\hline WA & $-65 \%(-20 \%,-85 \%) ; P=0.012$ & $-44 \%(43 \%,-78 \%) ; P=0.22$ \\
\hline SA & $28 \%(-13 \%, 90 \%) ; P=0.21$ & $-6 \%(50 \%,-41 \%) ; P=0.80$ \\
\hline ACT & $-41 \%(-11 \%,-61 \%) ; P=0.011$ & $-35 \%(5 \%,-60 \%) ; P=0.08$ \\
\hline
\end{tabular}

${ }^{*}$ Compared to pre-vacation period.

NSW, New South Wales; QLD, Queensland; VIC, Victoria; WA, Western Australia; SA, South Australia; ACT, Australian Capital Territory.

For the analysis of changes in weekly influenza counts from the previous week (as described in the statistical methods section, third paragraph) for all states combined, there were $19(33 \%)$ decreases pre-vacation; 11 (92\%) decreases during the vacation; and 19 (59\%) decreases post-vacation $(\mathrm{P}=0.0002)$.
The data on influenza rates by age group (Figure 2) show the first decline during school holidays is seen in the school aged (5-19 years) population, with the decline in the adult (20-64 years) population being smaller and following a further week later, and with even smaller and delayed drops in the 


\section{Influenza reports by age group}

9000

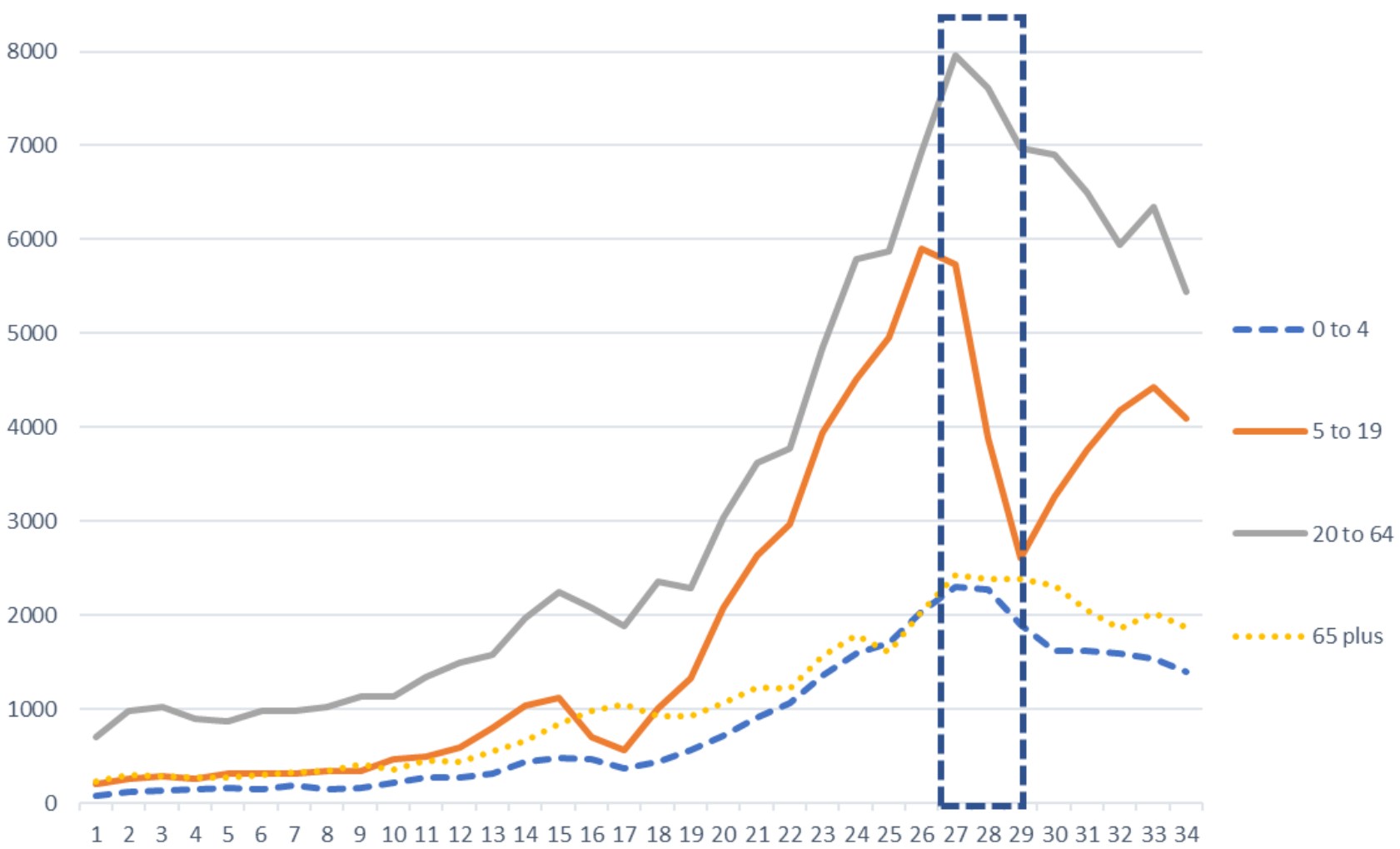

Figure 2. Influenza reports by age group (boxes show school holidays periods).

infant (1-4) and elderly (65+ years) age groups. We did not have access to the state specific age bands, and hence have indicated the school closure dates with the largest population groups.

\section{Discussion}

The 2019 Australia influenza notification data show a significant association between school holidays and declines in influenza incidence in most states in Australia. We also found the earliest and largest declines in influenza incidence were in the school aged group (5-19 years), with still later and smaller declines in the adult group (20-64), and least impact on the preschool and over 65's.

Our findings are consistent with previous reports ${ }^{3}$ of school closure for both usual holiday periods and emergency closure for epidemics.

The size of the declines is also consistent with those predicted by models of transmission for school closures ${ }^{18}$. Some states experienced a rebound within weeks of school restarting whereas others saw a continued decline. We do not have a simple explanation for this difference.

The association of school closure with declines in influenza has several potential explanations besides a causal effect. First, cases of influenza might be underreported because of delayed presentation or non-presentation during the school holiday period, for example, because with parents able to care for them they do not attend for medical certificates. However, if this were true, we would expect to see an immediate restart after school returns, which is not the case. Second, it could be because of other societal changes, such as parents also being on holiday and hence less transmission at work. However, if this were true, we would expect to see a simultaneous reduction in both child and adult cases. A final issue is that, even if reduction in incidence is real, it not clear whether there is a net annual decrease or merely a delay in total annual cases.

There are some limitations to both our data and the analysis. Good quality, numerical weekly flu data were unavailable for all states - e.g., South Australia reports its data as a mix of 
figures and numbers. This may have introduced some errors into the accuracy of the numbers for those states. We contacted the Australian National Notifiable Diseases Surveillance System, which coordinates the national surveillance of influenza in Australia, to obtain raw data for each state and territory. However, the raw data underlying the notifications for 2019 will not be available for release until July 2020 . There is also likely to be differences in the accuracy of different states' data, due to the different methods of collection. For the analysis, we used a lag of one week to allow for the delay from exposure to the virus to confirmation of infection status ${ }^{17}$. In a sensitivity analysis we refitted the model without a lag and produced consistent results (Appendix 5, Extended data) ${ }^{16}$.

Given the size of the effect, these results have important public health implications as no other intervention has comparable effects. Hence closure or extension of holiday periods could be an emergency option for state governments. In addition to encouraging flu vaccination, the Centres for Disease Control has a number of suggestions in their guidance, such as encouraging students and staff to stay home when sick, liberalising sickness policies during epidemics, encouraging respiratory etiquette, encouraging hand hygiene, regular cleaning of shared surfaces such as door handles and faucets, and providing a "sick room" to quarantine students with flu-like illnesses $^{19}$. An additional strategy is to consider face masks, which, with hand hygiene, appear to substantially reduce transmission. All these strategies would need to be triggered by health departments to schools at an appropriate point in an epidemic or pandemic.

\section{Data availability}

Underlying data

Bond University Research Portal: Australian state influenza notifications and school closures in 2019: Appendix 1 Underlying data. https://doi.org/10.26139/5c47ae4cd8e16 ${ }^{14}$

\section{Extended data}

Bond University Research Portal: Australian state influenza notifications and school closures in 2019: Appendix 2-5 - Extended data. https://doi.org/10.4225/57/555d781f8f2a $3^{16}$

Data are available under the terms of the Creative Commons Attribution 4.0 International license (CC-BY 4.0).

\section{Acknowledgements}

We would like thank Nancy Glasziou for pointing out the potential of school closure, and for comments on the manuscript.
1. Health Protection Agency: Weekly pandemic flue media update: 17 December 2009. 2009; [Accessed: 18 October 2019]. Reference Source

2. Ewing A, Lee EC, Viboud C, et al:: Contact, Travel, and Transmission: The Impact of Winter Holidays on Influenza Dynamics in the United States. $J$ Infect Dis. 2017; 215(5): 732-739.

PubMed Abstract | Publisher Full Text | Free Full Text

3. Jackson C, Vynnycky E, Hawker J, et al:: School closures and influenza: systematic review of epidemiological studies. BMJ Open. 2013; 3(2): pii: e002149. PubMed Abstract | Publisher Full Text | Free Full Text

4. Luca GD, Kerckhove KV, Coletti P, et al:: The impact of regular school closure on seasonal influenza epidemics: a data-driven spatial transmission model for Belgium. BMC Infect Dis. 2018; 18(1): 29. PubMed Abstract | Publisher Full Text | Free Full Text

5. Bin Nafisah S, Alamery AH, Al Nafesa A, et al:: School closure during novel influenza: A systematic review. J Infect Public Health. 2018; 11(5): 657-661. PubMed Abstract | Publisher Full Text

6. Australian Government: Australian national notifiable diseases and case definitions. 2019; [Accessed: 20 September 2019]. Reference Source

7. New South Wales Dept of Health: Influenza Surveillance Report. 2019; [Accessed: 20 September 2019]. Reference Source

8. Queensland Health: Influenza surveillance reporting. 2019; [Accessed: 20 September 2019]. Reference Source

9. ACT Government Department of Health: Flu in the ACT. 2019; [Accessed: 20 September 2019]. Reference Source

10. Government of Western Australia Dept of Health: Virus WAtch. 2019; [Accessed: 20 September 2019]. Reference Source
11. Victoria Department of Health: Seasonal Influenza Reports for 2019. 2019; [Accessed: 20 September 2019].

Reference Source

12. South Australia Health: Surveillance of notifiable conditions. 2019; [Accessed: 20 September 2019]. Reference Source

13. Rohatgi A: WebPlotDigitizer (Version 4.2). 2019; [Accessed: 25 September 2019]. Reference Source

14. Scott A, Bakhit M, Clark J, et al:: Australian state influenza notifications and school closures in 2019: Appendix 1 - Underlying data. Bond University. Scott_et_al_Australian_state_influenza_notifications_and_school_closures_in 2019_Appendix_1_Underlying_data(.xlsx), 2019 http://www.doi.org/10.26139/5c47ae4cd8e16

15. Gebski V, Ellingson K, Edwards J, et al.: Modelling interrupted time series to evaluate prevention and control of infection in healthcare. Epidemiol Infect. 2012; 140(12): 2131-41.

PubMed Abstract | Publisher Full Text

16. Scott A, Bakhit M, Clark J, et al:: Australian state influenza notifications and school closures in 2019: Appendix 2-5 - Extended data. Bond University. Appendix_2_5_Extended_data(.pdf), 2019. http://www.doi.org/10.4225/57/555d781f8f2a3

17. Centers for Disease Control and Prevention: Seasonal Influenza (Flu): How Flu Spreads. 2019a; [Accessed: 25 September 2019]. Reference Source

18. Jackson C, Mangtani P, Hawker J, et al:: The effects of school closures on influenza outbreaks and pandemics: systematic review of simulation studies. PLoS One. 2014; 9(5): e97297. PubMed Abstract | Publisher Full Text | Free Full Text

19. Centers for Disease Control and Prevention: Guidance for School Administrators to Help Reduce the Spread of Seasonal Influenza in K-12 Schools. 2019b; [Accessed: 25 September 2019]. Reference Source 


\section{Open Peer Review}

\section{Current Peer Review Status: ? ?}

\section{Version 1}

Reviewer Report 27 July 2020

https://doi.org/10.5256/f1000research.23276.r66760

(c) 2020 Torner $\mathbf{N}$. This is an open access peer review report distributed under the terms of the Creative Commons Attribution License, which permits unrestricted use, distribution, and reproduction in any medium, provided the original work is properly cited.

\section{Núria Torner \\ CIBER Epidemiology and Public Health CIBERESP, University of Barcelona, Barcelona, Spain}

Seasonal Influenza Surveillance deploying epidemiological and virological data on patients with influenza virus infection is a global task performed in coordination with WHO requirements. These include sentinel surveillance and hospital surveillance for severe cases of laboratory confirmed influenza. Even though influenza has been studied in depth, there are still some issues that need to be addressed, at least to encourage increase in vaccine uptake and recommendations.

There are several issues that are not clear and being this a point observation of just one season, inference is not sound enough to ascertain as evidence. Comparison with previous seasons would be desirable.

\section{Comments:}

1. One highly contrasted issue is the amplification that children trigger as to transmission of infection to their siblings and household members from the school setting. And this might be prevented by vaccination. (Basta et al. 2009) ${ }^{1}$. So this is not new but it might be relevant for Australia to implement preventive measures, if so this should be stated.

2. During epidemic periods transmission is high and the number of syndromic cases make laboratory confirmation out of range of heath systems. Is this so in Australia? As stated in data sources only laboratory confirmed cases are taken into account for reporting: States and territories differ in how they collect and report data on flu cases. New South Wales ${ }^{7}$ and Queensland ${ }^{8}$ report the number of samples that test positive for Influenza $A$ and $B$ (labconfirmed); Australian Capital Territory ${ }^{9}$ reports the number of influenza (lab) notifications to the state; and Western Australia ${ }^{10}$, Victoria ${ }^{11}$ and South Australia ${ }^{12}$ report the number of labconfirmed influenza cases (strains unspecified).

What is the difference between the three (besides type identification)? Positive for Influenza A and B (lab-confirmed); number of influenza (lab) notifications; and number of lab-confirmed influenza cases (strains unspecified). Do the authors mean type and subtype by strain? Or does it make reference to the strain type? 
Type A

Subtype A H1N1

Strain: A/Brisbane/59/2007 (H1N1)

Use the correct term.

3. There is also the climate factor to be taken into account. Do all regions included in the study have the same temperature, humidity range? Some differences in decrease of transmission could also be due to a lesser degree of transmission such as in Victoria and Southern Australia for example. Did this particular season have a different climatology that made it coincide with the school holiday period?

4. The results of the pre-school closure period refer to the baseline epidemic burden of disease, if so then there is a decline before school closure? By the way, the term school closure can be misleading as to a containment preventive measure that can be implemented to stop transmission and what is referred to in the study should be specific to school holiday closure. What has happened in other epidemic seasons should be included to be able to compare and strengthen the results obtained.

5. In the introduction first line: A pandemic is global, so it wasn't just the UK that was affected. As a matter of fact school closure emerged as one of the non-pharmaceutical strategies during that pandemic and has been implemented in the present COVID-19 pandemic. Sentence should be rephrased.

The authors findings could be in the same line as Eames $(2013)^{2}$ who stated that allowing some flexibility in holiday timing would provide maximum health benefit from the holiday period, yet this is difficult to carry out because of the different social and labor implications it has for schools, parents, and care givers. Was this the aim of the study?

6. In the conclusions the authors state that: no other intervention has comparable effects. There is no comparison in the study to other non-pharmaceutical mitigation measures. Can you include a reference to this statement?

\section{Minor comments:}

Include label on Figure 1, are they number of cases in total for all states or incidence rates? Please complete.

Why does Fig 1 have dates in the $x$-axis and Figure 2 the week number? Why different, they should be the same.

\section{References}

1. Basta NE, Chao DL, Halloran ME, Matrajt L, et al.: Strategies for pandemic and seasonal influenza vaccination of schoolchildren in the United States.Am J Epidemiol. 2009; 170 (6): 679-86 PubMed Abstract | Publisher Full Text

2. Eames KT: The influence of school holiday timing on epidemic impact.Epidemiol Infect. 2014; 142 (9): 1963-71 PubMed Abstract | Publisher Full Text

\section{Is the work clearly and accurately presented and does it cite the current literature?}


No

Is the study design appropriate and is the work technically sound?

Partly

Are sufficient details of methods and analysis provided to allow replication by others? Partly

If applicable, is the statistical analysis and its interpretation appropriate?

Yes

Are all the source data underlying the results available to ensure full reproducibility? Yes

Are the conclusions drawn adequately supported by the results?

Partly

Competing Interests: No competing interests were disclosed.

Reviewer Expertise: Surveillance, prevention and control of infectious disease outbreaks, with specific experience in seasonal influenza.

I confirm that I have read this submission and believe that I have an appropriate level of expertise to confirm that it is of an acceptable scientific standard, however I have significant reservations, as outlined above.

Author Response 24 Sep 2020

Anna Scott, Bond University, Robina, Australia

Thank you very much for your comments. We provide our responses below:

1. We agree that a multi-year comparison would be preferable. However, for 2020 , the number of flu infections is atypical (because of COVID), and for years prior to 2019, raw data is very difficult to obtain as it requires multiple data access applications to the individual states and to the Commonwealth. We have included the lack of control group as a limitation of the study, and provided a reference to a Government document comparing the trend from 2019 to years going back to 2013.

2. Thank you for providing this reference. We added the following sentence to the Discussion: "Vaccinating children against influenza has also been shown to substantially reduce influenza attack rates in both children and adults (Basta et al 2009)."

3. The relatively small size of the Australian population (approximately 25 million) makes laboratory confirmation a bit easier than in many other, more populous countries (e.g. in Europe, North America, South America). As we note in the methods section, we report lab-confirmed cases.

4. States/territories report influenzas a bit differently from each other. States of NSW and QLD report influenza A and influenza B only. ACT reports influenza A, influenza B, 
and coinfections with influenza A and B. The remaining states report lab-confirmed influenzas but do not specify strains. We have made this clearer in the text.

5. The temperatures were $1.6 \mathrm{deg}$ above the long-term average, in line with global warming but with no unusual anomaly in July 2019 (http://www.bom.gov.au/climate/mwr/aus/mwr-aus-201907.pdf). We do not have humidity data, but rainfall was lower than usual, suggesting lower humidity.

6. There was no decline before school closure - as Figure 1 shows, the decline only occurs within the grey boxes (the holiday periods). Any apparent decline - e.g. NSW is because we have joined the dots of the weekly reported numbers.

7. We have modified the title, and edited the body of the manuscript to refer to school holiday closures, to make this clearer.

8. We have replaced the term 'pandemic' with the term 'epidemic' in the first line of the introduction.

9. Eames' study used modelling to estimate a counterfactual: what would have happened if the UK had NOT closed the schools during the 2009 epidemic - and found the epidemic would have been much worse than it was. We estimated what happened with the actual school holiday closure in Australia - and found the influenza incidence decreased. Our study and Eames study are therefore consistent. We have added this point to the discussion section.

10. We added references to the newly updated Cochrane review by Tom Jefferson, on physical interventions to reduce the spread of respiratory viruses.

11. They are cases - we edited the figure and its title to clarify this.

12. We edited the figures so they both refer to dates for consistency.

Competing Interests: $\mathrm{n} / \mathrm{a}$

Reviewer Report 16 January 2020

https://doi.org/10.5256/f1000research.23276.r57787

(C) 2020 Bansal S et al. This is an open access peer review report distributed under the terms of the Creative Commons Attribution License, which permits unrestricted use, distribution, and reproduction in any medium, provided the original work is properly cited.

\section{Casey Zipfel}

Department of Biology, Georgetown University, Washington, DC, USA

\section{Shweta Bansal}

Department of Biology, Georgetown University, Washington, DC, USA

\section{Summary:}

Australia's influenza season does not typically coincide with school holidays. However, in 2019 , the influenza season occurred earlier than usual, allowing the opportunity to evaluate the impacts of school closure on influenza dynamics in Australia. In this article, the authors present state and 
territory-level influenza data by week, and perform segmented regression, comparing influenza incidence before and after the school holiday. They also count weekly increases and decreases before, during, and after the school holiday, and show age-based dynamics. This article asks an important question of public health relevance to non-pharmaceutical interventions in a setting where it has not been previously investigated in a concise manner. However, this article could be strengthened through additional framing, increased statistical rigor, and more nuanced interpretation.

\section{Comments:}

The introduction leaves several unanswered questions that would help to more clearly identify the importance of the study. The relationship between school closure and influenza dynamics has been explored in a number of previous papers, with both epidemiological data and mechanistic models. Thus, it is unclear to me why is it important to consider this relationship in Australia, specifically. Do the authors have hypotheses regarding trends or mechanisms that might be different from other countries? Is it important for public health planning? This question seems especially salient to me since school closures and the influenza season in Australia do not typically coincide, so these epidemiological trends may not be typical for Australia.

The article concludes that there is a significant reduction in influenza in most states in Australia based on the results of segmented regression comparing influenza incidence level and slope before and after the holiday period. I am not totally convinced by this conclusion, as Table 1 shows that the change in level is not significant for Victoria, Australian Capital Territory, and Southern Australia, and the change in slope is not significant for Queensland, Victoria, Western Australia, and Southern Australia. This is contrary to the section of the results that states that "the estimates for the initial effect and the subsequent slope show significant declines for all states except South Australia". These results could be more carefully interpreted. This would give rise to an interesting question: what are the differences between the states/territories that result in different dynamics?

I think this article could be strengthened with a more robust time series modeling approach, like ARIMA modeling. This would be particularly useful because the predicted vs. residual plot in Appendix 4 appears to indicate heteroskedasticity in the data. Including model terms in a time series model could handle this issue, as well as temporal autocorrelation.

The results also provide the percent of weeks in the pre-vacation, during-vacation, and postvacation period in which there is a weekly decrease in influenza incidence, indicating that there is a higher proportion of decreases in the during and post-vacation period. However, the pre-vacation period seems to include all of the early part of the season. If there were numerous decreases in this time period, then the onset of the influenza season would not have occurred. Thus, this finding may be a bit circular.

It would be useful to compare this influenza season, which co-occurs with the holiday period, with another influenza season that does not co-occur with the holiday period, as a control. This could help to isolate the impact of school closure on influenza dynamics.

The authors specify mid-May to early September as their study period. However, it's unclear 
what total population and age-specific dynamics looked like post week 35. Past studies have shown that school holidays simply delay dynamics so that the epidemic wave recovers to pre-holiday rates after the holiday. I would be curious if this is the case here.

In the model, a one-week lag was assumed. Is there evidence about care-seeking and influenza surveillance/reporting to support this? The discussion mentions a sensitivity analysis performed with no lag, but I wonder if the lag could be longer due to a combination of delay to seeking healthcare and delay in reporting.

The fourth paragraph of the discussion comments on the possible causes of the association between school closure and influenza. This paragraph rules out several possible explanations but does not then provide a plausible explanation.

\section{Minor comments:}

A y-axis label on Figure 1 and Figure 2 would be helpful. The Figure 1 caption says it is the influenza rate, so I assume it is influenza cases per week, but this could be clearer.

Is the $x$-axis in Figure 2 the week number? It would be easier to interpret if it was put into the same units as Figure 1, with dates instead of week counts.

Does Figure 2 include cases for all of the states and territories combined?

In Table 1, it is unclear whether the changes described (in both slope and level) are comparing the during-vacation period or the post-vacation period to the pre-vacation period. The observed and predicted plots in Appendix 3 appear to show 3 different segments fit for each of these periods, but it is unclear what change is reported in Table 1.

Is the work clearly and accurately presented and does it cite the current literature? Partly

Is the study design appropriate and is the work technically sound? Partly

Are sufficient details of methods and analysis provided to allow replication by others? Yes

If applicable, is the statistical analysis and its interpretation appropriate? Partly

Are all the source data underlying the results available to ensure full reproducibility? Yes

Are the conclusions drawn adequately supported by the results? Yes

Competing Interests: No competing interests were disclosed.

Reviewer Expertise: Modeling social and spatio-temporal dynamics of infectious disease, with 
specific experience in seasonal influenza.

We confirm that we have read this submission and believe that we have an appropriate level of expertise to confirm that it is of an acceptable scientific standard, however we have significant reservations, as outlined above.

Author Response 24 Sep 2020

Anna Scott, Bond University, Robina, Australia

Thank you very much for your comments. We provide our responses to each comment below:

1. We have added to the introduction the following: "Since each country's school system differs in features such as age range, classroom structure and sizes, and class mixing, we thought it important to document the size of any impact in Australia.

Furthermore, the variation by states, and the ability to examine delay to changes in the non-school population would extend the range of sub-questions we could address."

2. We agree, and have revised our interpretation of the results.

3. We are unfamiliar with ARIMA modelling, but generally prefer simpler approaches. Our main purpose for the statistical analysis is to test hypotheses for each state on whether the school closures have resulted in changes in levels and/or changes in slopes with regards to influenza cases. The goodness-of-fit measures suggest the regression models provide adequate fit hence we believe our results are valid.

4. We agree, and have removed this analysis from the manuscript.

5. Unfortunately we were unable to formally compare as the previous years' raw numbers are not readily available. We have included the lack of control group as a limitation of the study, and provided a reference to a Government document comparing the trend from 2019 to years going back to 2013.

6. We have included 1 additional month of data - up until the start of the October school holiday period.

7. A lag of 2 weeks would only be plausible if a person being exposed to influenza on the last week of school prior to the vacation would generally be reported at least 2 weeks and 3 days later. Given "symptoms can begin about 2 days (but can range from 1 to 4 days) after the virus enters the body" this delay seems unrealistic.

8. We agree, and have added the following: "Hence, the most likely remaining explanation seems to be causal reduction in transmission from school holidays."

9. Comments: 9-12. We have revised the Figures and Tables to address these comments.

Competing Interests: $\mathrm{n} / \mathrm{a}$ 
The benefits of publishing with F1000Research:

- Your article is published within days, with no editorial bias

- You can publish traditional articles, null/negative results, case reports, data notes and more

- The peer review process is transparent and collaborative

- Your article is indexed in PubMed after passing peer review

- Dedicated customer support at every stage

For pre-submission enquiries, contact research@f1000.com 